\title{
Total gas in-place calculations for the Baltic-Podlasie-Lublin basin shales in Poland
}

\author{
Marcin A. Lutynski ${ }^{1, a}$, and Miguel A. Gonzalez Gonzalez ${ }^{1}$ \\ ${ }^{1}$ Silesian University of Technology, Faculty of Mining and Geology, 44-100 Gliwice, Poland
}

\begin{abstract}
The total gas in-place calculations reflecting Polish reservoir conditions were performed using a corrected version for the free gas in-place, where not only the pore conditions were taken under consideration but also the volume that was already occupied by the sorbed gas. Shales show very different capacities between samples mainly due to in-situ conditions.
\end{abstract}

\section{Introduction}

During the first decade of XXI century and, to the lesser degree, also Canada experienced "energetic revolution" related to production of unconventional resources of gas and oil. A significant impact on gas and oil prices as well as in energy security was achieved due to the fast increase of production of these resources. Technologic and economic success of this sector of petroleum industry in North America has inspired attempts to export this concept to other continents, including Europe, at the beginning of the second decade of XXI century. Most intensive exploration of shale gas and oil, apart from US and Canade, took place in the Lower Paleozoic Baltic-Podlasie-Lublin Basin in Poland [1,2].

According to the International Energy Agency, Poland has become one of the countries with potentially the largest shale gas deposits. An accurate assessment of these deposits is a key factor to allow Poland to reduce the foreign dependency of this gas from Russia and other former Soviet republics $[3,4]$.

\section{Methodology}

In order to estimate the total gas in-place, equation 1 is used.

$$
G_{s t}=G_{a}+G_{f}
$$

This equation is divided in volumetric and surface components. In this equation $G_{s t}$ is the total gas inplace, $G_{f}$ is the volumetric component involving hydrocarbons stored in the pore space as free gas, and $G_{a}$ is the surface component, with the gas physically adsorbed on the large surface area of the micropores [5].

\footnotetext{
${ }^{a}$ Corresponding author: Marcin.Lutynski@polsl.pl
} 
The surface component is calculated using equation:

$$
G_{a}=G_{L} \cdot \frac{p}{p+p_{L}}
$$

where $G_{L}$ is the Langmuir volume, $p$ is the pressure and $p_{L}$ is the Langmuir pressure. Equation 3 is used to calculate the volumetric component,

$$
G_{f}=\frac{32,0368}{B_{g}}\left[\frac{\emptyset\left(1-S_{w}\right)}{\rho_{b}}-\frac{1,318 \times \widehat{10^{-6}} M}{\rho_{s}}\left(G_{L} \frac{p}{p+p_{L}}\right)\right]
$$

where $B_{g}$ is the gas formation volume factor, $\phi$ is the porosity of the rock, $S_{w}$ the water saturation, $M$ the molar mass, $\rho_{b}$ the bulk rock density and $\rho_{s}$ the sorbed phase density.

This model takes under consideration, not only the adsorbed gas, but also the free gas stored inside the pores to give a more accurate value of the total gas in-place. It is particularly important that, unlike in coals, the ratio of adsorbed gas-to-free gas is much lower. For calculation of the total free gas inplace, the adsorbed gas must be calculated and subtracted from this calculation and corrected for the water saturation [5]. This methodology may give a new overview on the comprehensive assessment of $\mathrm{CH}_{4}$ potential of Polish shales as a strategic reservoir for $\mathrm{CH}_{4}$.

\section{Calculations and results}

Two samples were tested with completely different parameters as shown in Table 1. Sorption measurements were performed using the high precision manometric sorption setup, located in the Institute of Mining at the Silesian University of Technology (Figure 1.) Calculations of the sorption capacities and Langmuir models are shown in Fig. 2.

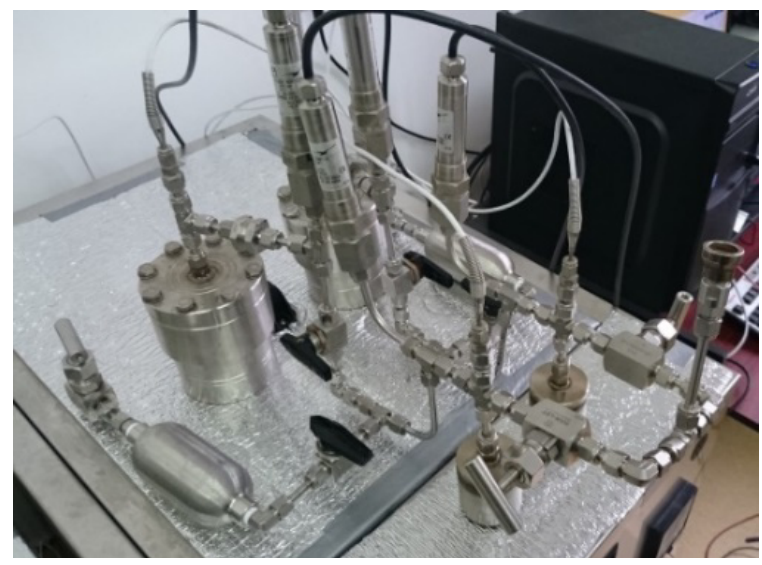

Figure 1. High precision manometric setup at the Silesian University of Technology, Poland.

Parameters related to the in-situ conditions of the basin were supplied by the drilling company and some of them are shown in Table 1.

Taking under consideration the in-situ characteristics of the basin and the tests performed in the laboratory both components of Equation (1) were calculated. The surface component, dependent on the sorption capacities, and thus on the rock composition, showed proportional values to the sorption capacities calculated with $2.06 \mathrm{sm}^{3} / \mathrm{t}$ for sample no. 1 and $3.37 \mathrm{sm}^{3} / \mathrm{t}$ for sample no. 2 . The volumetric component mostly depended on the porosity and water saturation of the samples. It greatly impacted the results obtained for sample no. 1 with only $0.12 \mathrm{sm}^{3} / \mathrm{t}$ of free gas, while sample no. 2 had 3.92 $\mathrm{sm}^{3} / \mathrm{t}$ of free gas. These results are shown in Figure 3 for comparison. 


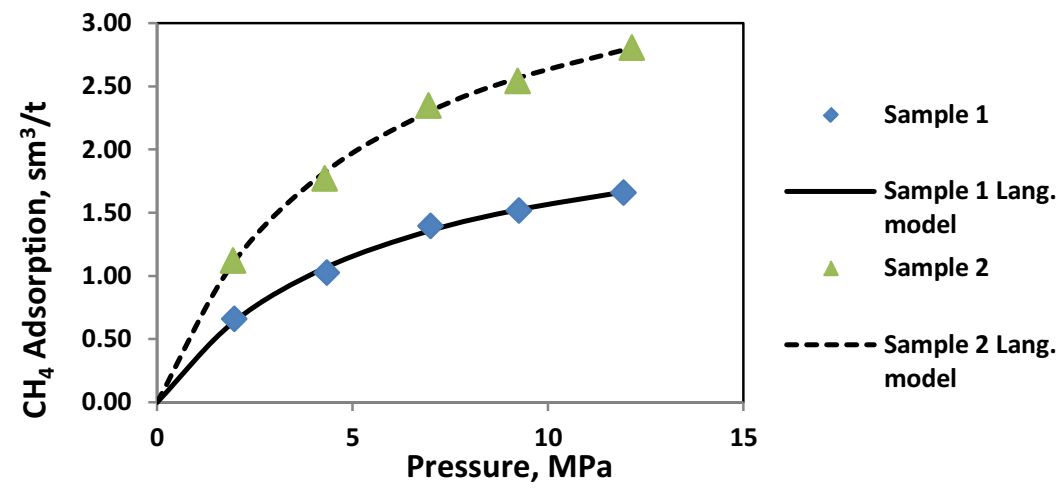

Figure 2. Methane sorption measurements and Langmuir model for Polish shales.

Table 1. Some of the in-situ parameters of the samples.

\begin{tabular}{|l|c|c|}
\hline & Sample 1 & Sample 2 \\
\hline Porosity, \% & 5.16 & 9.50 \\
\hline $\begin{array}{l}\text { Water saturation, } \\
\%\end{array}$ & 70.61 & 35.00 \\
\hline $\begin{array}{l}\text { Bulk rock density, } \\
\text { g/cm }\end{array}$ & 2.67 & 2.40 \\
\hline $\begin{array}{l}\text { Total Organic } \\
\text { Carbon, \% }\end{array}$ & 1.25 & 4.19 \\
\hline
\end{tabular}

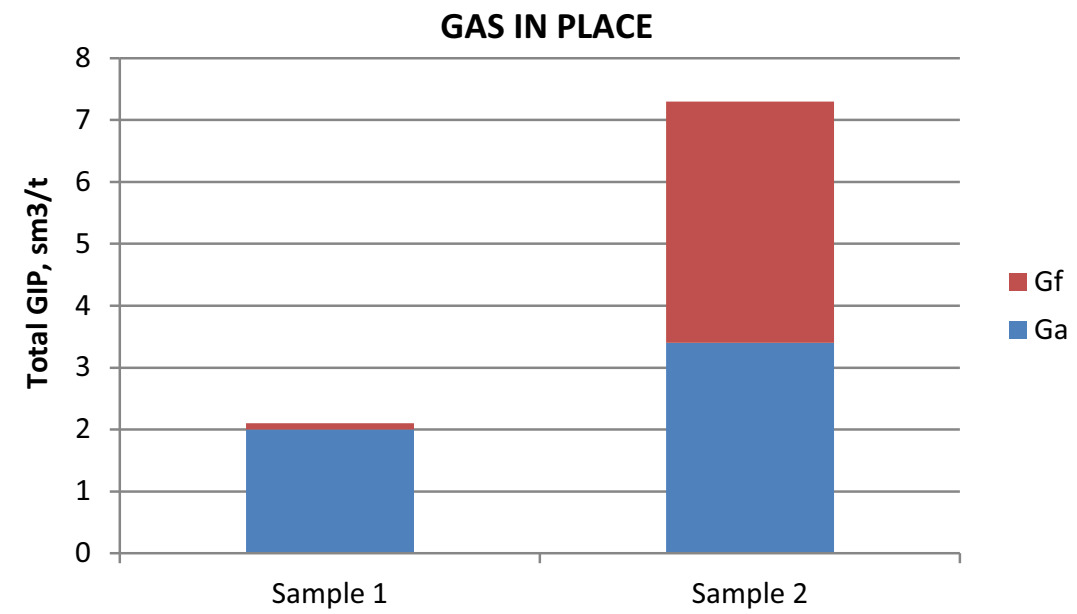

Figure 3. Results obtained in the total gas-in-place calculations.

\section{Results and conclusions}

Results obtained in the study showed that the biggest impact while calculation of the total GIP, was not produced by the rock composition, but by the basin conditions. Thus, a sample that during a preliminary analysis may seem to be the worse choice due to its composition, could be as good as 
higher organic matter sample under the adequate conditions. In the data exposed, it can be observed that sample no. 2 is better than sample no. 1, related to the surface component, by a $70 \%$. However when taking under consideration the free gas, this value increases up to $250 \%$,

To get a better idea of this, we decided to apply the basin data from sample no. 2 to the sample no. 1, with a hypothetical result of gas-in-place of $6.7 \mathrm{sm}^{3} / \mathrm{t}$. These new values are shown in Figure 4 . With these suppositions, the total gas in place difference, due to the rock composition, is reduced.

For the correct understanding of the data, the subtracting factor from Equation 3 has to be taken under consideration. The higher the sorption capacity, the lower total free gas calculation. It is due to the volume of pore that is taken by the sorbed gas on the surface of pores.

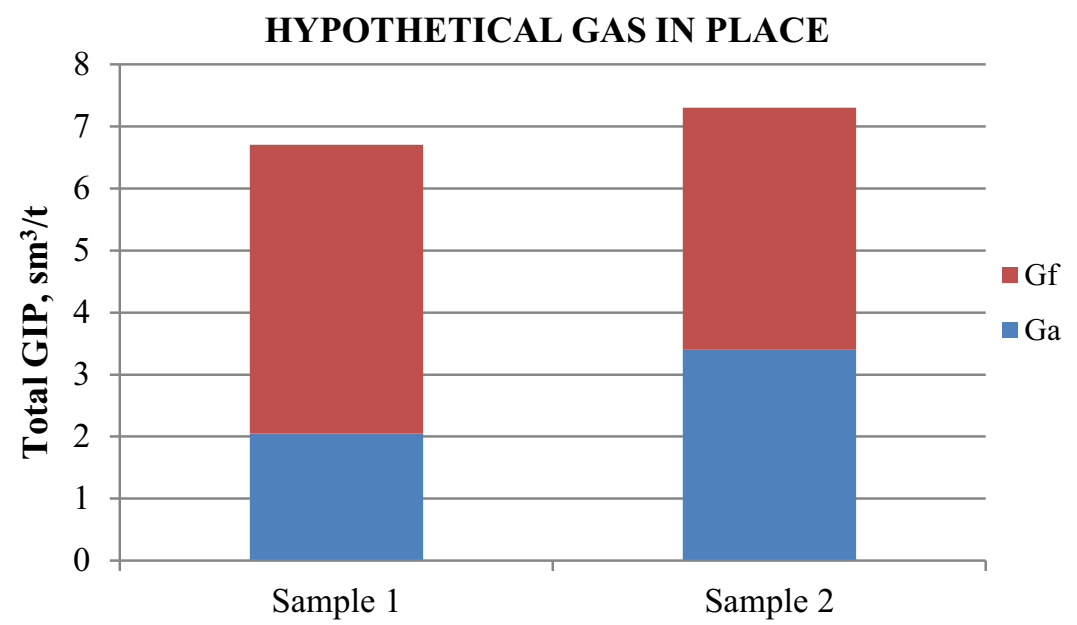

Figure 4. Hypothetical results obtained using the same main parameters for both samples.

\section{Acknowledgments}

The research leading to these results has received funding from the Polish-Norwegian Research Programme operated by the National Centre for Research and Development under the Norwegian Financial Mechanism 2009-2014 and Project Contract No. PL12-0109.

\section{References}

1. Assessment of shale gas and shale oil resources of the Lower Paleozoic Baltic-Podlasie-Lublin basin in Poland (Polish Geological Institute, 2012)

2. Oil and Gas in Poland, new opportunities, (Polish Geological Institute, 2015)

3. World Shale Gas Resources: An Initial Assessment of 14 Regions Outside the United States, (EIA, 2011)

4. Natural Gas: Information. (EIA, 2015)

5. R.J. Ambrose, R.C. Hartman, M. Diaz-Campos, I. Yucel Akkutlu and C.H. Sondergeld, in proccedings of SPE Unconvencional Gas Conference (SPE 131722, 2010). 